\title{
PENGARUH PENGEMBANGAN OBYEK WISATA TERHADAP KEPUASAN WISATAWAN PANTAI AKKARENA KOTA MAKASSAR
}

\author{
Muhammad Arhan Rajab ${ }^{1}$, Rusmin Nuryadin ${ }^{2}$ \\ Jurusan Manajemen Pariwisata, Sekolah Tinggi Pariwisata (STIPAR) Tamalatea \\ Jl. Perintis Kemerdekaan Km. 12 Makassar \\ Email Korespondensi : arhanrajab@stipartamalatea.ac.id
}

\begin{abstract}
ABSTRAK
Penelitian ini bertujuan untuk mengetahui apakah ada Pengaruh antara pengembangan obyek wisata terhadap kepuasan wisatawan pada objek wisata Pantai Akkarena di Kecamatan Tamalate Kota Makassar. Penelitian ini dilaksanakan Pada objek wisata Pantai Kota Makassar, yang menjadi populasi adalah semua pengunjung yang berkunjung pada Tahun 2019 yaitu sebanyak 1.250 orang. Untuk menentukan sampel yang akan dijadikan responden ditetapkan dengan rumus Slovin sebanyak 100 orang wisatawan, sedangkan teknik pengumpulan data digunakan metode kuesioner dan interviuw, sedangkan analisis datanya menggunakan statistik infrensial Korelasi Product Moment dengan rumus angka kasar (rXY). Hasil analisis data menunjukkan bahwa pengaruh Pengembangan Wisata terhadap Kepuasan Wisatawan mempunyai korelasi kuat ditunjukkan dengan koefisien korelasi rhitung sebesar 0,716 ternyata $>$ (lebih besar) dari rtabel sebesar 0,195 pada taraf signifikan 5\% dan sebesar 0,254 pada taraf signifikan 1\%. Dan dari hasil perhitungan koefisien determinasi diperoleh bahwa variabel Pengembangan Obyek Wisata (X) memberi pengaruh sebesar 51,26 \% terhadap variabel Kepuasan Wisatawan (Y), sedangkan selebihnya yaitu sebesar $48,74 \%$ adalah dipengaruhi oleh variabel-variabel lain yang tidak turut diteliti dalam penelitian ini.
\end{abstract}

Kata Kunci: wisata pantai, kepuasan, wisatawan, pantai akkarena.

\begin{abstract}
This study aims to determine whether there is an influence between the development of tourism objects on tourist satisfaction at the Akkarena Beach tourist attraction in Tamalate District, Makassar City. This research was conducted on the tourist attraction of Makassar City Beach, which became the population of all visitors who visited in 2019 as many as 1,250 people. To determine the sample to be the respondent was determined by the Slovin formula as many as 100 tourists, while the data collection techniques used questionnaires and interview methods, while the data analysis used statistical product moment correlation with the rough number formula $(r X Y)$. The results of data analysis show that the influence of tourism development on tourist satisfaction has a strong correlation, indicated by the correlation coefficient rcount of 0.716 , in fact> (greater) than the r table of 0.195 at the $5 \%$ significant level and 0.254 at the $1 \%$ significant level. And from the calculation of the coefficient of determination, it is found that the Tourism Object Development variable (X) has an effect of $51.26 \%$ on the Tourist Satisfaction variable $(Y)$, while the remaining $48.74 \%$ is influenced by other variables which are not examined in the this research.
\end{abstract}

Keywords: beach tourism, satisfaction, tourists, beach akkarena 


\section{PENDAHULUAN}

Pariwisata dapat menjadi sarana dalam mewujudkan pembangunan berkelanjutan melalui gerakan atau usaha-usaha yang lebih nyata. Salah satu usaha yang dilakukan adalah melalui penerapan konsep-konsep pariwisata berkelanjutan. pentingnya kepuasan pelanggan untuk bisnis pariwisata dan kebutuhan untuk upaya yang dapat dilakukan dalam rangka memenuhi harapan pelanggan. Ini berarti bahwa memuaskan harapan wisatawan dengan meningkatkan standar keramahan dan kualitas layanan pariwisata dapat membayar kembali hal menyebarkan Words of Positif Mouth bagi pelanggan potensial, yang, pada gilirannya, adalah biaya yang efektif dan lebih dapat diandalkan dibandingkan jenis lain dari iklan (Agyeiwaah., et all, 2016).

Sulawesi Selatan memiliki potensi untuk memperoleh keuntungan dari sektor pariwisata karena posisinya yang sangat strategis untuk memasuki daerah tujuan wisata di kawasan timur Indonesia. Sentra utama pembangunan kepariwisaataan Sulawesi Selatan meliputi Makassar, Tana Toraja, dan Bulukumba. Salah satu daerah yang termasuk wilayah pengembangan pariwisata (WPP) Sulawesi Selatan ialah Kota Makassar memiliki obyek dan daya tarik wisata (ODTW) yang sangat beragam seperti obyek wisata alam dan wisata budaya. Keberagaman obyek itu memerlukan usaha pengembangan untuk diberdayakan sehingga mampu menarik wisatawan domestik maupun mancanegara (Dinas Pariwisata Kota Makassar, 2019).

Salah satu obyek wisata yang ada Kota Makassar adalah Pantai Akkarena. Kawasan pantai yang dibangun menjadi tempat wisata akan mengalami perubahan lingkungan baik secara nyata maupun tidak, terlebih apabila pembangunan kawasan pantai diikuti dengan beberapa aktivitas lain, seperti tempat pemukiman, pelelangan ikan, kuliner masakan laut, dan sekaligus menjadikan tempat rekreasi bagi wisatawan (Nawawi, 2013)

Tujuan penelitian ini adalah Tujuan penelitian ini adalah untuk mengetahui pengaruh pengembangan obyek wisata Pantai Akkarena Di Kecamatan Tamalate Kota Makassar terhadap kepuasan wisatawan.

\section{METODE PENELITIAN}

\section{Waktu dan Lokasi}

Penelitian ini dilaksanakan pada bulan November-Desember 2019 dan lokasi penelitian adalah Pantai Akkarena, Kota Makassar Sulawesi Selatan.

\section{Jenis dan Sumber Data}

Penelitian ini dilakukan dengan metode survey dan studi literatur dimana data bersumber dari data primer yakni data yang dikumpulkan melalui observasi dan pengukuran langsung di lapangan dan data sekunder yang bersumber dari instansi terkait dengan pengelolaan Pantai Akkarena sebagai kawasan wisata

\section{Teknik Pengumpulan Data}

Untuk memperoleh data yang dibutuhkan penulis menggunakan 3 jenis pengumpulan data, yaitu :

1. Observasi, 
Observasi adalah merupakan kegiatan penelitian dimana penulis mengadakan pengamatan langsung terhadap obyek yang diteliti.

2. Dokumentasi

Dokumentasi adalah merupakan kegiatan penelitian dimana penuis memperoleh sejumlah data melalui bahan dokumentasi tertulis mengenai hal-hal yang relevan dengan kebutuhan penulis.

3. Interview

Interview adalah merupakan kegiatan dimana penulis mengadakan wawancara langsung dengan masyarakat di sekitar obyek wisata dengan tujuan mendapatkan informasi dan data yang lebih jelas.

\section{Analisis Data}

Untuk mengetahui adakah pengaruh pengembangan obyek wisata budaya terhadap kepuasan wisatawan, maka data yang terkumpul dianalisis dengan produk moment Person dengan rumus sebagai berikut :

Dimana :

$$
\mathbf{r x y}=\frac{\sum x y}{\sqrt{\left(\sum x^{2}\right)\left(\sum y^{2}\right)}}
$$

rxy = Angka indeks korelasi " $r$ " product moment

$\sum \mathrm{x}^{2}=$ Jumlah Deviasi skor $\mathrm{x}$ setelah terlebih dahulu dikuadratkan

$\sum \mathrm{y}^{2}=$ Jumlah Deviasi skor y setelah terlebih dahulu dikuadratkan

Sedangkan interprestasi indeks korelasi product moment dicantumkan dalam Tabel berikut :

Tabel. Interpretasi indeks korelasi product moment.

\begin{tabular}{l|l}
\hline Interval Koefisien & Tingkat Hubungan \\
\hline $\pm 0,80-1,00$ & Sangat kuat \\
\hline $\pm 0,60-1,99$ & Kuat \\
\hline $\pm 0,40-0,59$ & Cukup kuat \\
\hline $\pm 0,20-0,399$ & Rendah \\
\hline $\pm 0,00-0,199$ & Sangat rendah \\
\hline
\end{tabular}

Sumber : Riduan (2004).

Selanjutnya untuk menentukan seberapa besar pengaruh variabel bebas terhadap variabel terikat, maka digunakan "Koefisien Determinasi " dengan rumus : 
Dimana :

$$
K P=\mathbf{r}^{2} \mathbf{X} 100 \%
$$

$$
\begin{array}{ll}
\mathrm{Kp}= & \text { Nilai Koefosien Determinan } \\
\mathrm{r}= & \text { Nilai Koefisien Korelasi }
\end{array}
$$

\section{HASIL DAN PEMBAHASAN}

\section{Obyek Wisata Pantai Akkarena Kota Makassar}

Pantai Akkarena merupakan bagian dari ekosistem pesisir pantai Makassar dengan kemiringan datar (0-3\%) pada ketinggian 1-4 m di atas permukaan laut. Kondisi geologi terbentuk dari endapan alluvium yang bersifat kurang kompak sampai agak lepas. Di sekitar pantai terdapat empang yang dipengaruhi air hujan. Jenis tanah terdiri dari tanah inseptisol dan ultisol. Sebagian besar tanah pada umumnya merupakan tanah inseptisol (Nurfaida, 2009). Pantai Akkarena merupakan pantai yang ramai dikunjungi oleh masyarakat. Fasilitas yang disediakan di Pantai Akkarena pun merupakan hal-hal utama yang dibutuhkan kawasan wisata guna terlaksananya kegiatan wisata.

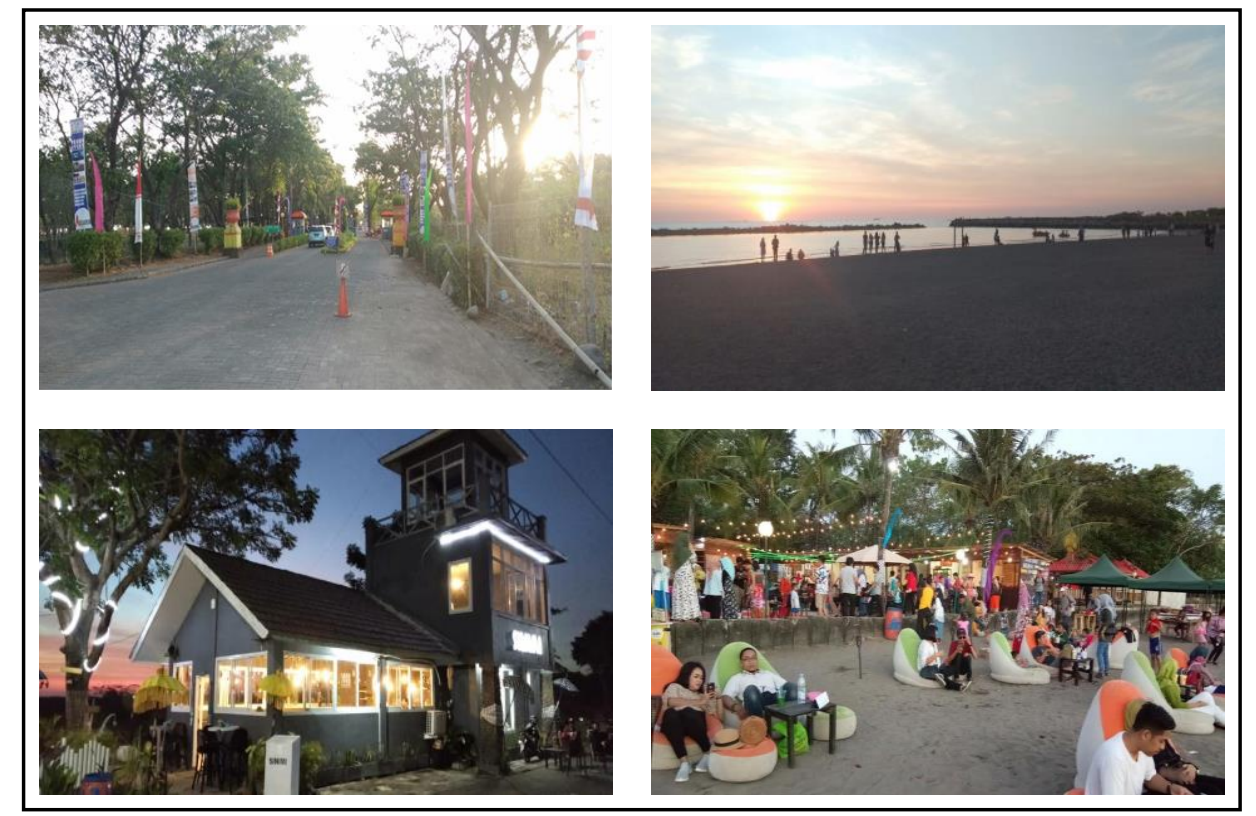

Gambar 1: Kondisi Wisata Pantai Akkarena Kota Makassar

\section{Analisis Data}

Teknik analisis data yang digunakan adalah "Korelasi Product Moment Pearson" dengan rumus angka kasar. Dengan metode korelasi tersebut akan dicari kuatnya pengaruh terhadap kedua variabel, yaitu:

a). Variabel pertama adalah menyangkut Pengembangan Obyek Wisata merupakan variabel bebas dan diberi simbol (X).

b). Variabel kedua adalah menyangkut Kepuasan Wisatawan yang merupakan variabel terikat dan diberi simbol (Y). 
Analisis yang digunakan adalah analisa statistik maka kuatnya pengaruh terhadap variabel X dan Y tersebut dinyatakan dengan bilangan. Bilangan yang menyatakan besar kecilnya pengaruh itu disebut koefisien korelasi yang biasanya diberi simbol (rxy).

Untuk memperoleh koefisien korelasi tersebut, maka terlebih dahulu dibuatkan tabel kerja koefisien korelasi antara variabel X dan Y. Untuk mencari koefisien korelasi maka digunakan rumus angka kasar sebagai berikut :

$$
\mathbf{r x y}=\frac{\sum x y}{\sqrt{\left(\sum x^{2}\right)\left(\sum y^{2}\right)}}
$$

Untuk mengetahui masing-masing komponen didalam rumus tersebut maka dapat dihitung :

$$
\begin{aligned}
& \sum \boldsymbol{x}^{2}=\sum \boldsymbol{x}^{2}-\left(\sum \boldsymbol{x}\right)^{2} \frac{\left(\sum x\right)^{2}}{N} \\
& \sum y^{2}=\sum y^{2}-\left(\sum y\right)^{2} \frac{\left(\sum y\right)^{2}}{N} \\
& \sum x y=\sum x y-\frac{\left(\sum x\right) \cdot\left(\sum y\right)}{\mathrm{N}}
\end{aligned}
$$

Berdasarkan pada tabel kerja koefisien korelasi lampoiran 6, maka telah diketahui :

$$
\begin{array}{llc}
\sum X=\mathbf{3 . 5 0 6} & \sum X^{2}=\mathbf{1 2 3 . 1 3 8} & \sum X Y=103.917 \\
\sum Y=\mathbf{2 . 9 5 9} & \sum Y^{2}=\mathbf{8 7 . 8 2 9} & \mathbf{N}=\mathbf{1 0 0}
\end{array}
$$

Dengan menggunakan rumus di atas, maka dapat dihitung $\sum \mathbf{X}^{2}, \sum \mathbf{Y}^{\mathbf{2}}$ dan $\sum \mathbf{X} \mathbf{Y}^{\mathbf{2}}$ sebagai berikut :

$$
\begin{aligned}
& \text { Nilai } \begin{aligned}
\sum x^{2}= & \sum x^{2}-\left(\sum x\right)^{2} \frac{\left(\sum x\right)^{2}}{N} \\
\sum x^{2}= & 123.138-\frac{(3506)^{2}}{100} \\
& \sum x^{2}=123.138-\frac{12.292 .036}{100} \\
& \sum x^{2}=123.138-122920,36 \\
& \sum x^{2}=\mathbf{2 1 7 , 6 4}
\end{aligned}
\end{aligned}
$$

Nilai $\sum y^{2}=\sum y^{2}-\left(\sum y\right)^{2} \frac{\left(\sum y\right)^{2}}{N}$

$$
\begin{aligned}
\sum y^{2}= & 87.829-\frac{(2959)^{2}}{100} \\
& \sum y^{2}=87.829-\frac{8.755 .681}{100} \\
& \sum y^{2}=87.829-87556,81 \\
& \sum y^{2}=\mathbf{2 7 2 , 1 9}
\end{aligned}
$$

Nilai $\sum x y=\sum x y-\frac{\left(\sum x\right) \cdot\left(\sum y\right)}{\mathrm{N}}$

$$
\begin{aligned}
& \sum x y=103917-\frac{(2959)(2959)}{100} \\
& \sum x y=103917-\frac{(10374254)}{100} \\
& \sum x y=103917-103742,54 \\
& \sum x y=\mathbf{1 7 4}, \mathbf{4 6}
\end{aligned}
$$

Dari hasil perhitungan diatas maka telah diketahui : 


$$
\begin{aligned}
& \sum x^{2}=217,64 \\
& \sum y^{2}=272,19 \\
& \sum x y=174,46
\end{aligned}
$$

Maka koefisien korelasi (rxy) dapat dihitung sebagai berikut :

$$
\begin{aligned}
& \mathbf{r x y}=\frac{\sum x y}{\sqrt{\left(\Sigma x^{2}\right)\left(\Sigma y^{2}\right)}} \\
& \mathbf{r x y}=\frac{174,46}{\sqrt{(217,64)(272,19)}} \\
& \mathbf{r x y}=\frac{174,46}{\sqrt{59239,431}} \\
& \mathbf{r x y}=\frac{174,46}{243,39151} \\
& \mathbf{r x y}=\mathbf{0 , 7 1 3}
\end{aligned}
$$

Berdasarkan pada kualitas pengaruh tersebut maka koefisien korelasi yang telah ditemukan yaitu : Kualitas pengaruh antara variabel Pengembangan obyek Wisata (X) dengan variabel Kepuasan Wisatawan (Y) ditunjukkan dengan koefisien korelasi sebesar 0,716 atau mempunyai korelasi kuat artinya dengan adanya pengembangan obyek wisata di Objek Wisata Pantai Akkarena dapat berimplikasi pada kepuasan wisatawan yang berkunjung ke objek wisata tersebut.

\section{KESIMPULAN DAN SARAN}

\section{Kesimpulan}

Berdasarkan hasil analisis data bahwa Pengembangan Obyek Wisata berpengaruh terhadap kepuasan wisatawan pada obyek wisata Pantai Akkarena Kota Makassar, mempunyai korelasi sangat kuat yaitu sebesar 0,716 yang mana lebih besar dari rtabel sebesar 0,195 pada taraf signifikan 5\% dan sebesar 0,254 pada taraf signifikan $1 \%$, dengan obyek wisata berpengaruh terhadap kepuasan wisatawan pada obyek wisata Pantai Akkarena Kota Makassar dinyatakan "diterima”.

\section{Saran}

Perlu penelitian lebih lanjut terkait dengan dampak sosial ekonomi terhadap masyarakat yang ada di sekitar Pantai Akkarena Kota Makassar.

\section{UCAPAN TERIMA KASIH}

Ucapan terima kasih kami ucapkan kepada seluruh pengelola kawasan wisata Pantai Akkarena Kota Makassar dan para pengunjung yang bersedia kami wawancarai atas bantuan untuk memberikan izin melakukan penelitian dan Terima kasih tak lupa kami sampaikan kepada Dinas Pariwisata Kota Makassar dalam menyediakan data-data pendukung penelitian. 


\section{DAFTAR PUSTAKA}

Agyeiwaah, E., et al. (2016). Make customer, not a sale: Tourist satisfaction in Hongkong. Tourism Management 57 (2016): 68-79.

Dinas Pariwisata Kota Makassar. (2019). Potensi Pariwisata di Kota Makassar. Makassar Sulawesi Selatan.

Nawawi, Ahmad. (2013). Partisipasi Masyarakat dalam Pengelolaan Wisata Pantai Depok di Desa Kretek Parangtritis. Jurnal Nasional Pariwisata.

Nurfaida, (2009). Pengembangan Dan Rencana Pengelolaan Lanskap Pantai Kota Makassar Sebagai Waterfront City. Sekolah Pascasarjana Institut Pertanian Bogor. Bogor (ID). 